\title{
Lithium-lon (de)insertion reaction of Germanium thin-film electrodes : an electrochemical and in situ XRD study
}

\section{Citation for published version (APA):}

Baggetto, L., \& Notten, P. H. L. (2009). Lithium-Ion (de)insertion reaction of Germanium thin-film electrodes : an electrochemical and in situ XRD study. Journal of the Electrochemical Society, 156(3), A169-A175. https://doi.org/10.1149/1.3055984

DOI:

10.1149/1.3055984

Document status and date:

Published: 01/01/2009

\section{Document Version:}

Publisher's PDF, also known as Version of Record (includes final page, issue and volume numbers)

\section{Please check the document version of this publication:}

- A submitted manuscript is the version of the article upon submission and before peer-review. There can be important differences between the submitted version and the official published version of record. People interested in the research are advised to contact the author for the final version of the publication, or visit the $\mathrm{DOI}$ to the publisher's website.

- The final author version and the galley proof are versions of the publication after peer review.

- The final published version features the final layout of the paper including the volume, issue and page numbers.

Link to publication

\section{General rights}

Copyright and moral rights for the publications made accessible in the public portal are retained by the authors and/or other copyright owners and it is a condition of accessing publications that users recognise and abide by the legal requirements associated with these rights.

- Users may download and print one copy of any publication from the public portal for the purpose of private study or research.

- You may not further distribute the material or use it for any profit-making activity or commercial gain

- You may freely distribute the URL identifying the publication in the public portal.

If the publication is distributed under the terms of Article 25fa of the Dutch Copyright Act, indicated by the "Taverne" license above, please follow below link for the End User Agreement:

www.tue.nl/taverne

Take down policy

If you believe that this document breaches copyright please contact us at:

openaccess@tue.nl

providing details and we will investigate your claim. 


\title{
Lithium-Ion (De)Insertion Reaction of Germanium Thin-Film Electrodes: An Electrochemical and In Situ XRD Study
}

\author{
Loïc Baggetto ${ }^{\mathrm{a}, \mathrm{z}}$ and Peter H. L. Notten ${ }^{\mathrm{a}, \mathrm{b}, *}$ \\ ${ }^{a}$ Department of Chemical Engineering and Chemistry, Eindhoven University of Technology, $5600 \mathrm{MB}$ \\ Eindhoven, The Netherlands \\ ${ }^{b}$ Philips Research Laboratories, 5656 AE Eindhoven, The Netherlands
}

\begin{abstract}
Germanium is a promising negative electrode candidate for lithium-ion thin-film batteries because of its very high theoretical storage capacity. When assuming full conversion of the material into the room-temperature equilibrium lithium saturated germanium phase $\mathrm{Li}_{22} \mathrm{Ge}_{5}$, a theoretical capacity of $1625 \mathrm{mAh} \mathrm{g}^{-1}$ or $8643 \mathrm{mAh} \mathrm{cm}^{-3}$ of germanium starting material is expected However, the lithium-ion (de)insertion reaction of pure germanium thin films and the resulting electrochemical thermodynamic and kinetic properties are not yet fully understood. To address some of these questions, a combined electrochemical and in situ $\mathrm{X}$-ray diffraction (XRD) study is presented. Results on the crystallographic phase transitions, occurring upon Li-(de)insertion of evaporated and sputtered germanium thin films are discussed. Moreover, the difference in reaction between evaporated and sputtered films is addressed. In addition, a detailed electrochemical investigation (cyclic voltammetry, galvanostatic intermittent titration technique, and electrochemical impedance spectroscopy) of evaporated germanium is conducted. The results reveal that evaporated and sputtered germanium crystallizes into $\mathrm{Li}_{15} \mathrm{Ge}_{4}$ when fully inserted with $\mathrm{Li}$ ions. This composition corresponds to a maximum storage capacity of $1385 \mathrm{mAh} \mathrm{g}^{-1}$ or $7366 \mathrm{mAh} \mathrm{cm}^{-3}$ of germanium starting material.
\end{abstract}

(C) 2009 The Electrochemical Society. [DOI: 10.1149/1.3055984] All rights reserved.

Manuscript submitted September 30, 2008; revised manuscript received November 21, 2008. Published January 9, 2009.

Nowadays there is a growing need for high storage capacity and high power density solid-state lithium-ion microbatteries. ${ }^{1-4}$ Indeed, future medical implants and other crucial upcoming applications will require small and power-dense portable energy supplies. Obviously, the electrode materials of such a battery should be able to store a large amount of $\mathrm{Li}$ while maintaining a good cyclability and high rate capability.

Negative electrodes of existing planar solid-state thin-film lithium-ion batteries usually consist of pure metallic lithium. ${ }^{2-5}$ The rate capability of lithium is very high in comparison with alloying materials. However, others issues, such as safety and packaging, should be improved. At the moment, many groups are investigating suitable Li-ion negative electrode materials for bulk and thin-film applications, for example, silicon-, germanium-, and tin-based materials. ${ }^{3-36}$ These group-IV materials are ideal candidates with respect to storage capacity, as they can store more than $7000 \mathrm{mAh} \mathrm{cm}{ }^{-3}$ of the starting material. Moreover, silicon and germanium thin films have demonstrated a high rate capability.,

The Li-ion electrochemistry of silicon-based electrodes has been thoroughly studied. ${ }^{2-4,11-25}$ Germanium electrodes have received little attention in the existing literature because of the high cost of the material. ${ }^{6-10}$ However, for application in thin-film batteries the amount of electrode material is not a critical issue. Moreover, germanium presents several advantages over silicon, such as a two orders of magnitude higher diffusivity for lithium and a four orders of magnitude higher electronic conductivity. ${ }^{6,10}$ Germanium has mainly been studied toward electrochemical potential profiles, capacity retention, rate capability, and crystallographic phase transitions. ${ }^{6-10}$ This material could be a suitable negative electrode material for all-solid-state Li-ion thin-film batteries. ${ }^{6-8}$ Moreover, Graetz et al. attempted to identify the crystallographic phases formed upon (de)inserting germanium thin-films using ex situ X-ray diffraction (XRD). However, these attempts were unfortunately unsuccessful. $^{6}$

Recently, two other groups studied the phase transitions of Gebased bulk electrodes with ex situ XRD. ${ }^{9,10}$ The first group focused on the fully lithiated electrode material and found evidence for the crystallization of germanium into cubic $\mathrm{Li}_{15} \mathrm{Ge}_{4}$ as an end member of the electrochemically induced $\mathrm{Li}-\mathrm{Ge}$ system.
similar to that of silicon, which crystallizes into cubic $\mathrm{Li}_{15} \mathrm{Si}_{4}{ }_{18,19}$

\footnotetext{
* Electrochemical Society Active Member

${ }^{\mathrm{z}}$ E-mail: 1.baggetto@tue.nl
}

The second group investigated Ge-based bulk electrodes as a function of the Li composition also by means of ex situ XRD. ${ }^{10}$ They clearly revealed the formation of $\mathrm{Li}_{15} \mathrm{Ge}_{4}$ but also reported supporting evidence of the formation of other $\mathrm{Li}-\mathrm{Ge}$ phases on the basis of a few diffraction peaks only. For the fully loaded electrode, the formation of $\mathrm{Li}_{22} \mathrm{Ge}_{5}$ was supported by a single diffraction peak at $2 \theta=40.6^{\circ}$. This is rather ambiguous as the positions of the strongest calculated diffraction peak for $\mathrm{Li}_{7} \mathrm{Ge}_{2}$ and $\mathrm{Li}_{22} \mathrm{Ge}_{5}$ are the same, at exactly $2 \theta=40.65^{\circ}$ (Pauling File Binaries edition, Data sheets S1250775 and S457785, respectively for $\mathrm{Li}_{7} \mathrm{Ge}_{2}$ and $\mathrm{Li}_{22} \mathrm{Ge}_{5}$ ). Moreover, both studies were conducted ex situ and no particular precaution toward air and water was reported in the corresponding experimental sections.

Using a sealed cell to determine the phase transformations of germanium during (de)lithiation by means of in situ XRD offers several advantages over the setups employed by other groups., 10 First, air and water contamination are prevented. Moreover, by adopting thin layers of pure germanium, the electrochemical control of the Li-Ge stoichiometry is much more accurate. Indeed, opposite to bulk composite electrodes, no binders or conductive additives interfering with the desired $\mathrm{Li}-\mathrm{Ge}$ reaction are employed.

In this paper, we report on various aspects of the $\mathrm{Li}(\mathrm{de})$ insertion of germanium thin-film electrodes. The reactions observed when inserting/extracting lithium into/from evaporated germanium will be discussed. The thermodynamic and kinetic properties were electrochemically measured by using cyclic voltammetry $(\mathrm{CV})$ and the galvanostatic intermittent titration technique (GITT), coupled with electrochemical impedance spectroscopy (EIS). In addition, in situ electrochemical XRD of evaporated germanium thin layers will be presented. Moreover, it has been found that sputtered germanium reveals different electrochemical properties than evaporated germanium, which might be related to a different reaction mechanism. In situ XRD will therefore also be presented for sputtered germanium films.

\section{Experimental}

Thin-film deposition.- Two electrochemical measurement setups were employed. The first setup was used to determine the electrochemical characteristics of germanium thin films, while the second setup served the in situ electrochemical XRD measurements. For both setups, the germanium thin films were grown using the same deposition conditions. 
The first setup employed $\mathrm{n}^{++}$silicon substrates covered by $70 \mathrm{~nm}$ of titanium nitride. In this configuration, titanium nitride was used as a current collector and Li-diffusion barrier layer. ${ }^{3}$ Subsequently, $50 \mathrm{~nm}$ thick germanium layers were deposited by either sputtering or evaporation.

The in situ XRD setup used XRD-amorphous polyetheretherketone (PEEK) foils of $125 \mu \mathrm{m}$ thickness as substrates (GoodFellow). Prior to the deposition of titanium nitride and germanium, a thin titanium layer of $5 \mathrm{~nm}$ was sputtered onto the PEEK foil. This layer was used as an adhesion layer for the subsequently deposited materials. As this film is rather thin, no interfering diffraction lines are expected from titanium. Titanium adhesion layers were sputtered in a Veeco Nexus 800 chamber. The base pressure was $6.7 \times 10^{-8}$ mbar. Using a 12 in. titanium target, $100 \mathrm{~W}$ dc power, a deposition pressure of $2.6 \times 10^{-3} \mathrm{mbar}$, and an Ar flow of $50 \mathrm{sccm}$, titanium was deposited at $0.13 \AA \mathrm{s}^{-1}$. Then, a titanium nitride film of $200 \mathrm{~nm}$ was grown on top of the titanium film by reactive sputtering in a nitrogen plasma, using conditions reported elsewhere. ${ }^{3}$ Finally, germanium films from 100 to $800 \mathrm{~nm}$ were either evaporated or sputtered on top of the titanium nitride. Using an E-beam evaporation tool (Bak550 from Balzers, Liechtenstein) at a base pressure of $10^{-7}$ mbar and a deposition pressure of $4 \times 10^{-7} \mathrm{mbar}$, germanium thin films were evaporated at a rate of $2 \AA \mathrm{s}^{-1}$. Using a sputtering tool from Emerald at a base pressure of $10^{-6}$ mbar, a deposition pressure of $5.2 \times 10^{-3}$ mbar and an Ar flow of $70 \mathrm{sccm}$, germanium thin films were sputtered from an 8 in. germanium target with a radio-frequency power of $200 \mathrm{~W}$ at a rate of $0.5 \AA \mathrm{s}^{-1}$.

Electrochemical characterization.-For both electrochemical setups, the germanium electrodes were mounted as working electrodes while pure lithium foils were used as counter and reference electrodes. A liquid electrolyte, comprising $1 \mathrm{M} \mathrm{LiClO}_{4}$ dissolved in propylene carbonate (Puriel, Techno Semichem Co. Ltd., Korea) was used. All electrochemical measurements were conducted with Autolab PGSTAT30 equipment (Ecochemie B.V., Utrecht, The Netherlands). The following convention is adopted throughout the article: charging the electrode material refers to $\mathrm{Li}$ insertion and discharging to Li extraction. All potentials are written with respect to $\mathrm{Li} / \mathrm{Li}^{+}$standard redox potential.

The first setup employed a three-electrode cylindrical cell, made of Teflon having a volume of about $40 \mathrm{~mL}$. The circular germanium electrodes $\left(\phi=2 \mathrm{~cm}^{2}\right)$ were assembled in an argon-filled glove box with water and oxygen content below $1 \mathrm{ppm}$. The cells were placed in a stainless steel holder that was thermostatically controlled at $25^{\circ} \mathrm{C}$. This setup was used to determine the equilibrium voltage curves and the electrode impedance of germanium electrodes, using GITT and EIS, respectively, and cyclic voltammograms. GITT was performed by applying approximately 40 successive increments of charge at a $1 \mathrm{C}$ rate, followed by intermediate rests of $1.5 \mathrm{~h}$. Two cutoff potentials were applied during the galvanostatic steps of the GITT, i.e., 50 and $0 \mathrm{mV}$. EIS was performed after each GITT resting period, using an excitation voltage of $5 \mathrm{mV}$ amplitude within a frequency range of $100 \mathrm{kHz}$ and $100 \mathrm{mHz}$. The impedance results were fitted using an equivalent circuit software tool. $\mathrm{CV}$ was performed at a scan rate of $50 \mu \mathrm{V} \mathrm{s}^{-1}$ between 0 and 1 or $2 \mathrm{~V}$.

The in situ XRD setup comprised a specially designed cell made of poly(vinylidene fluoride). The body of the cell is identical to that of Vermeulen et al. ${ }^{37}$ Inside an argon-filled glove box, a PEEK foil, covered with the previously described layers, was attached to one side of the cell body. Then, the body was filled with the same electrolyte described above. The foil attachment system ensured a proper electrical contacting of the germanium films via a copper ring, which is sealed from the electrolyte with an O-ring. Subsequently, pure lithium ribbons (Sigma Aldrich) were attached to crocodile clamps placed under a newly designed cover and introduced in the solution. Very thin metallic wires, soldered to the crocodile clamps, allowed the external electrical contacting of the lithium ribbons as reference and counter electrodes. Finally, the

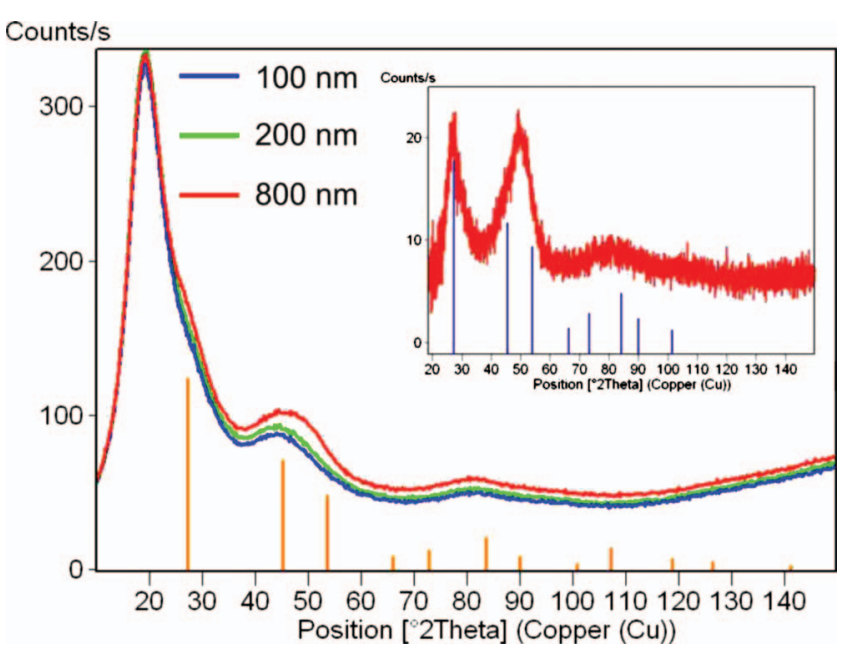

Figure 1. Ex situ XRD patterns of as-deposited Ge films evaporated on PEEK foils covered by $5 \mathrm{~nm}$ of Ti. The film thicknesses are indicated in the figure. The inset shows the subtraction of the XRD pattern corresponding to a $800 \mathrm{~nm}$ thick film by the pattern corresponding to a $100 \mathrm{~nm}$ thick film. The reference diffraction peaks for Ge diamond structure are indicated as bars.

cover of the cell was placed and sealed by means of an additional O-ring in the same way used by Vermeulen et al. ${ }^{37}$

XRD experiments. - Ex situ XRD was measured on freshly deposited samples made of PEEK/Ti/Ge germanium films using a Panalytical XPert Pro diffractometer equipped with a $\mathrm{Cu}$ source to generate $\mathrm{K} \alpha$ radiation $(1.54 \AA)$. The in situ electrochemical XRD cell was mounted on a Philips PW 1835 horizontal diffractometer. Gonio $(\theta-2 \theta)$ scans were recorded using a $\mathrm{Cu}$ source to generate $\mathrm{K} \alpha$ radiation. Each in situ XRD scan was recorded from 18 to $54^{\circ}$ in $75 \mathrm{~min}$.

\section{Results and Discussion}

The crystallinity of the starting evaporated germanium material was measured with ex situ XRD on samples with different thickness. The main graph of Fig. 1 presents diffraction patterns for the 100, 200, and $800 \mathrm{~nm}$ films. No sharp peaks are visible, which indicates that evaporated germanium presents a disordered structure (amorphous). To eliminate the substrate background, the diffraction patterns of the thickest and thinnest layers were subtracted (inset of Fig. 1). As a consequence, broad peaks corresponding to the germanium diamond structure are observed. This result is similar to those reported by Laforge et al. for sputtered germanium films. ${ }^{7}$ It can be concluded that the starting evaporated material has a poor crystalline structure.

The electrochemical response of the evaporated germanium films was measured for different insertion cutoff potentials using $\mathrm{CV}$ at $50 \mu \mathrm{V} \mathrm{s}^{-1}$. The results corresponding to $50 \mathrm{~nm}$ thick films are presented in Fig. 2. Several broad peaks are observed during reduction (insertion or charge) down to $300 \mathrm{mV}$, followed by a more pronounced peak at about $150 \mathrm{mV}$ (blue curve). Further insertion of $\mathrm{Li}$ leads to a small and sharp peak around $50 \mathrm{mV}$ (orange curve). During oxidation (deinsertion or discharge), reversible peaks are found for the phases formed down to $300 \mathrm{mV}$. The reduction peak at about $150 \mathrm{mV}$ is, however, accompanied by a rather broad peak during delithiation (blue curve). Strikingly, the small peak at about $50 \mathrm{mV}$ induces very sharp oxidation peaks at about 485 and $525 \mathrm{mV}$. For comparison, silicon reveals only two broad peaks when the material is lithiated until $50 \mathrm{mV}$, and upon further charging this system shows a small plateau representative of the crystallization into $\mathrm{Li}_{15} \mathrm{Si}_{4} \cdot{ }^{3,4,18,19}$ During Li extraction from $\mathrm{Li}_{15} \mathrm{Si}_{4}$, a single peak response is observed. ${ }^{3}$ This situation is rather different from that of the evaporated germanium, where a double peak system is found. 


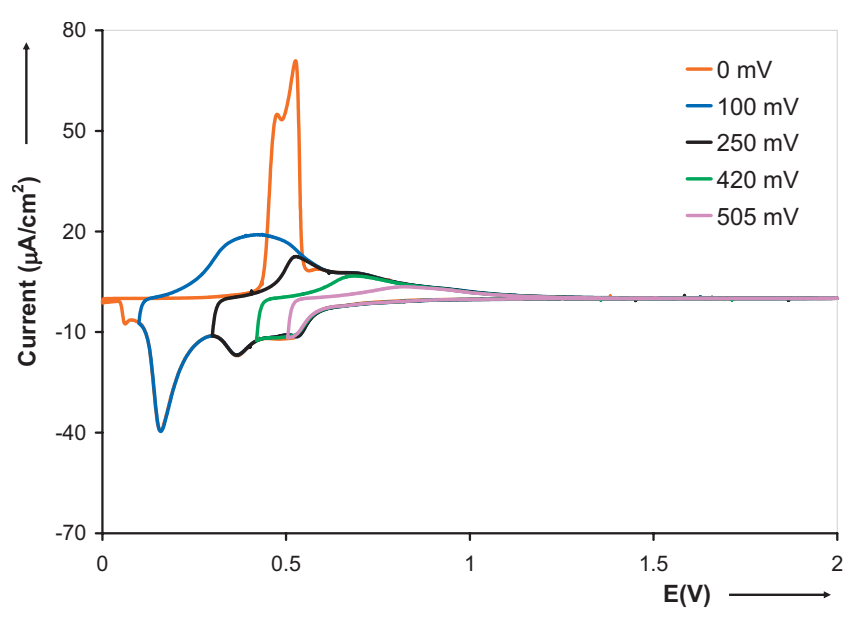

Figure 2. Cyclic voltammograms of a $50 \mathrm{~nm}$ thick evaporated $\mathrm{Ge}$ film at various insertion cutoff potentials. The scan rate is $50 \mu \mathrm{V} \mathrm{s}^{-1}$ and the upper cutoff potential is $2 \mathrm{~V}$ in all cases.

Laforge et al. only observed a single-peak response during the deinsertion of fully lithiated sputtered germanium thin films.

To characterize the crystallographic phases formed during $\mathrm{Li}$ insertion, in situ XRD was conducted on $200 \mathrm{~nm}$ thick films. Figure 3a shows a typical potential profile obtained for evaporated germanium during the first insertion/extraction of $\mathrm{Li}$. The electrode was charged with a constant current of about a $1 / 25 \mathrm{C}$ rate followed by a resting period. Subsequently, the electrode was discharged at the same rate. A voltage plateau is clearly found around $1 \mathrm{~V}$, which can be attributed to the formation of a solid electrolyte interphase (SEI) layer. Further charging leads to several sloping parts, which correspond to the small peaks found in the CVs of Fig. 2. Upon further lithiation, a large quasi-plateau is visible from 15 to $23 \mathrm{~h}$, which corresponds to the pronounced peak in Fig. 2. At the end of the insertion process, a small plateau is found, which is analogous to the small and sharp peak observed at $50 \mathrm{mV}$ in Fig. 2. During the extraction of Li from the fully lithiated germanium electrode, two plateaus can be discerned, corresponding to the two peaks reported above. Upon further extraction of $\mathrm{Li}$, a steeper potential response is measured at higher voltages.

During the galvanostatic (dis)charging of the germanium electrode, XRD patterns were collected. The starting time of each diffraction pattern is indicated in the potential curve of Fig. 3a by markers. The corresponding patterns are plotted in Fig. 3b and c for insertion and deinsertion, respectively. The direction of Li insertion/ extraction into/from the electrode material is indicated by the arrows. First, all patterns indicate a strong reflection peak at $36.5^{\circ}$ which corresponds to the (111) diffraction of titanium nitride. Moreover, the as-deposited material does not exhibit any clear sharp peaks related to germanium, as already concluded from the ex situ XRD patterns (Fig. 1). Upon insertion (Fig. 3b), no peaks are visible in the patterns until the potential reaches $110 \mathrm{mV}$, which corresponds to the small plateau visible at the very end of charging (Fig. $3 a)$. The associated diffraction peaks match very well the reference pattern of cubic $\mathrm{Li}_{15} \mathrm{Ge}_{4}$. Upon deinsertion (Fig. 3c), the peaks associated with $\mathrm{Li}_{15} \mathrm{Ge}_{4}$ reduce in intensity and no peaks for other crystalline $\mathrm{Li}-\mathrm{Ge}$ phases are observed.

In an effort to precisely determine the end member of the electrochemically induced $\mathrm{Li}-\mathrm{Ge}$ phase, the discharged electrode was lithiated potentiostatically in two successive steps at 130 and $20 \mathrm{mV}$. These potential values correspond to the situations before and after the crystallization into $\mathrm{Li}_{15} \mathrm{Ge}_{4}$. The corresponding current (red curve) and charge (blue curve) responses are shown in the inset of Fig. 4. A decrease of the current during both potentiostatic steps is found, indicating that the insertion reactions proceed relatively rapidly. The corresponding XRD results are presented in the main graph
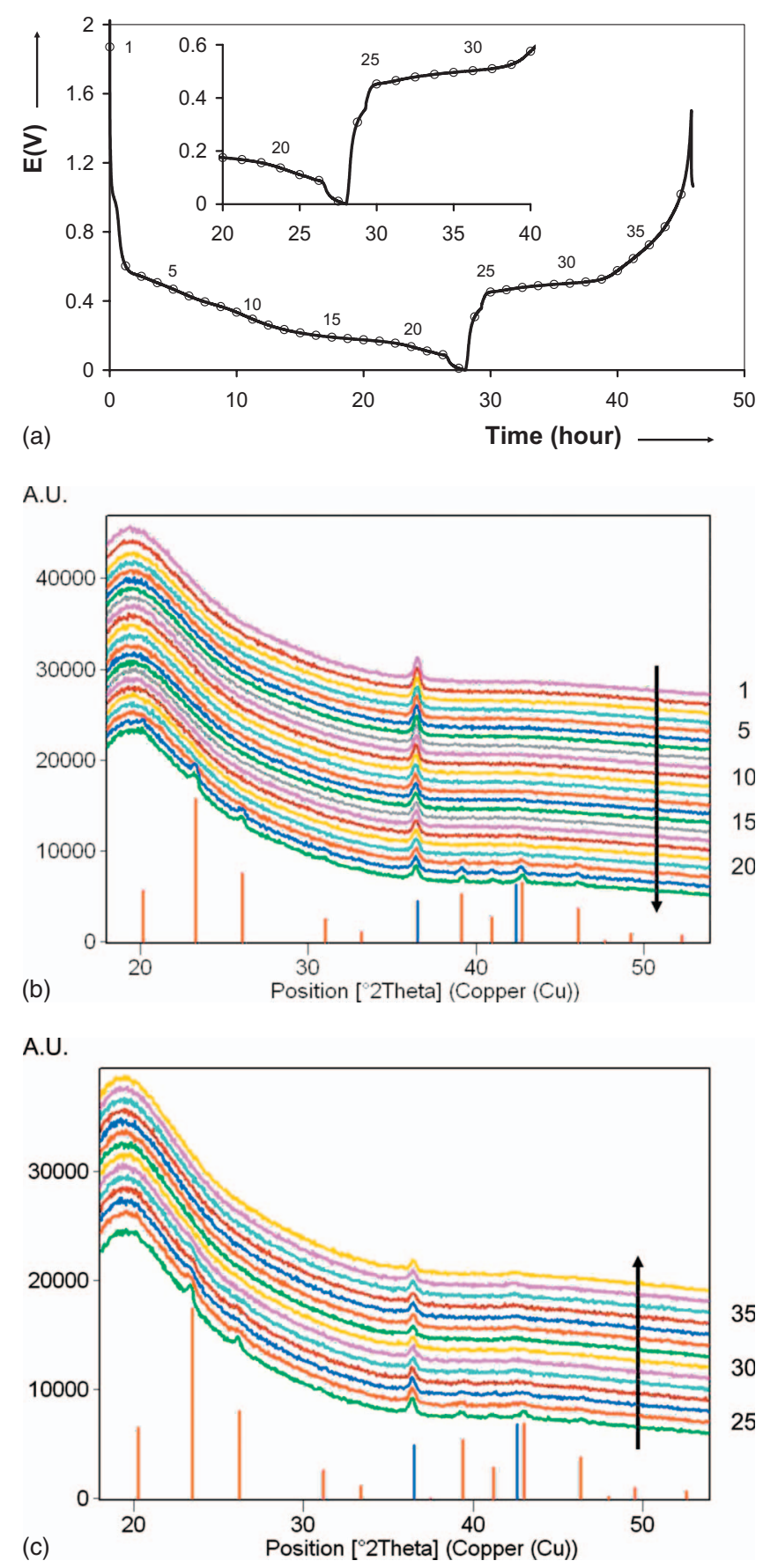

Figure 3. In situ XRD characterization of a $200 \mathrm{~nm}$ thick evaporated Ge film. (a) Galvanostatic insertion and deinsertion of the film. The inset is a magnification of the potential curve at low voltages. Each marker represents the start of an XRD measurement. (b) XRD patterns corresponding to insertion. (c) XRD patterns corresponding to deinsertion. The reference patterns for $\mathrm{TiN}$ (blue) and $\mathrm{Li}_{15} \mathrm{Ge}_{4}$ (orange) are indicated as bars.

of Fig. 4. The XRD patterns of the as-deposited (pink curve) and discharged (green curve) electrode are included as references. Taking a closer look at the pattern of the as-deposited sample, a strong (111) preferred orientation of the titanium nitride crystallites is found at $36.5^{\circ} 2 \Theta$. Interestingly, the discharged electrode reveals a weaker (111) intensity and a reflection of the $\{200\}$ lattice planes is now visible at $42.5^{\circ} 2 \Theta$. The modification of the titanium nitride crystallites orientation probably results from the stress induced by the expansion/shrinkage of the germanium layer onto the underlying titanium nitride. 


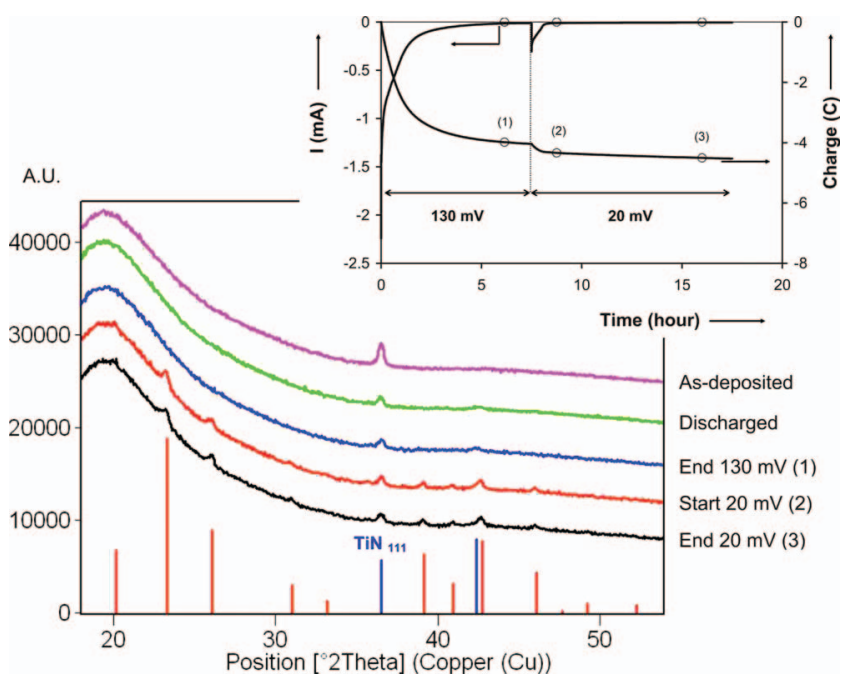

Figure 4. XRD patterns measured during the potentiostatic insertion of a cycled germanium electrode in two successive steps at 130 and $20 \mathrm{mV}$. The inset shows the current and charge evolution as a function of time during the potentiostatic steps. Each marker represents the start of an XRD scan. Patterns from top to bottom: as-deposited germanium, discharged germanium after 1 cycle, (1) at the end of the potentiostatic step at $130 \mathrm{mV}(2)$, at the start of the potentiostatic step at $20 \mathrm{mV}$, and (3) at the end of the potentiostatic step at $20 \mathrm{mV}$. The reference patterns for $\mathrm{TiN}$ (blue) and $\mathrm{Li}_{15} \mathrm{Ge}_{4}$ (red) are indicated as bars.

Regarding the phase transformations occurring within the germanium film, the pattern collected at the end of the first potentiostatic step at $130 \mathrm{mV}$ (blue curve in Fig. 4), which corresponds to the situation when $\mathrm{Li}_{15} \mathrm{Ge}_{4}$ has not yet been formed, does not reveal any peaks associated with $\mathrm{Li}-\mathrm{Ge}$ phases. This is in accordance with the constant current measurements presented in Fig. 3. When the potential is decreased to $20 \mathrm{mV}$, the material rapidly shows an XRD signature of $\mathrm{Li}_{15} \mathrm{Ge}_{4}$, as observed from the pattern collected at the start of the second potentiostatic step (red curve). The pattern collected at the end of the potentiostatic step at $20 \mathrm{mV}$ (black curve) does not show any additional reflections. In addition, the charge transferred to the germanium layer between the two XRD patterns taken at $20 \mathrm{mV}$ is negligible. From these results, it can be concluded that no other crystalline $\mathrm{Li}-\mathrm{Ge}$ phases are formed before and after the crystallization into $\mathrm{Li}_{15} \mathrm{Ge}_{4}$.

A thicker evaporated germanium layer $(500 \mathrm{~nm})$ was also investigated with in situ XRD. Using a thicker film can be useful in revealing the formation of crystalline phases with weak diffraction intensities. As presented in the inset of Fig. 5, the sample was galvanostatically charged with a current of less than a $1 / 40 \mathrm{C}$ rate to ensure full lithiation. The main graph of Fig. 5 shows the diffraction pattern measured just before the plateau at the end of the charging process [blue curve denoted as (a)] and the pattern measured after full lithiation [red curve denoted as (b)], as indicated by the markers in Fig. 5. Before the plateau, no diffraction peaks, except that of titanium nitride, are visible. After full lithiation, until the cell potential reached $0 \mathrm{~V}$, peaks related to cubic $\mathrm{Li}_{15} \mathrm{Ge}_{4}$ are observed. The intensity of the peaks resulting from a $500 \mathrm{~nm}$ thick layer is obviously substantially increased. To conclude, other Li-Ge crystalline phases are not clearly observed for evaporated germanium thin films.

The thermodynamic and kinetic properties of evaporated germanium are presented in Fig. 6. Because the crystallization of germanium into $\mathrm{Li}_{15} \mathrm{Ge}_{4}$ induces relatively different potential profiles (cf. Fig. 2), the equilibrium curves were measured with GITT for two cutoff potentials, i.e., 50 (orange curve) and $0 \mathrm{mV}$ (blue curve) (Fig. 6a). Upon insertion, several slopes are observed from 650 to $115 \mathrm{mV}$ up to a $\mathrm{Li} / \mathrm{Ge}$ ratio of about $3.69 \mathrm{Li} / \mathrm{Ge}$, which

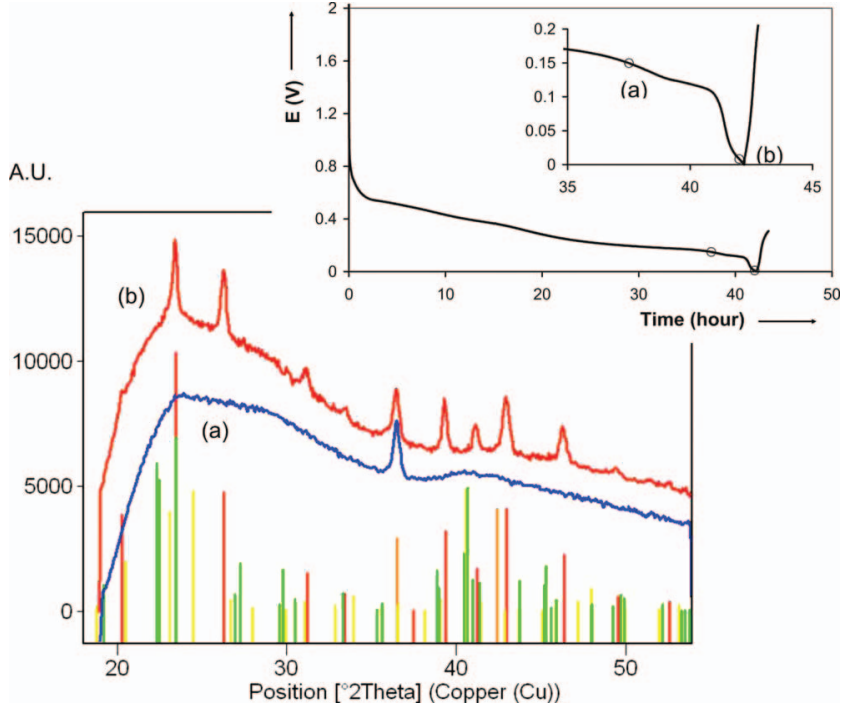

Figure 5. In situ XRD characterization of a $500 \mathrm{~nm}$ thick evaporated Ge film. XRD patterns (a) before and (b) after the plateau observed at low potentials, as indicated by the markers in the inset. The inset shows the galvanostatic insertion of the film. A magnification of the potential curve at the end of the charging process is included in the inset. The markers indicate the start of the XRD scans. The reference patterns for TiN (blue), $\mathrm{Li}_{7} \mathrm{Ge}_{2}$ (green), $\mathrm{Li}_{15} \mathrm{Ge}_{4}$ (red), and $\mathrm{Li}_{22} \mathrm{Ge}_{5}$ (yellow) are indicated as bars.

probably represent XRD-amorphous transformation(s) (cf. Fig. 3). When the potential is restricted to $50 \mathrm{mV}$ during current flowing conditions, the discharge curve also reveals several sloping parts (blue curve) ultimately leading to a reversible $\mathrm{Li} / \mathrm{Ge}$ ratio of about $3.57 \mathrm{Li} / \mathrm{Ge}$. When the electrode is fully inserted up to $0 \mathrm{~V}$, the $\mathrm{Li} / \mathrm{Ge}$ ratio increases to about 3.85. As a result, crystallization into $\mathrm{Li}_{15} \mathrm{Ge}_{4}$ occurs. The $\mathrm{Li}$ extraction of the electrode from $\mathrm{Li}_{15} \mathrm{Ge}_{4}$ material is represented by two rather flat plateaus until the composition reaches about $1.85 \mathrm{Li} / \mathrm{Ge}$ (orange curve). Upon further $\mathrm{Li}$ extraction, a sloping profile is again observed until the full extraction of $\mathrm{Li}$ from Ge occurs. This full extraction leads to a reversible $\mathrm{Li} / \mathrm{Ge}$ ratio of about $3.73 \mathrm{Li} / \mathrm{Ge}$. The inset of Fig. 6a shows the derivative of the $\mathrm{Li} / \mathrm{Ge}$ ratio with respect to the potential. Obviously, the shape of the derivatives is very similar to the cyclic voltammograms in Fig. 2. During equilibrium, however, the potential is not influenced by the overpotentials and the delithiation peaks are therefore found at somewhat more negative potentials (390 and $450 \mathrm{mV}$ ).

The flat plateaus observed during discharge are attractive in view of making batteries with more stable cell voltages. However, crystallization of the material may shorten the lifetime of the electrode as it induces severe local stresses at the boundaries between the amorphous and crystalline domains. Nevertheless, this may not be a critical issue if an appropriate thickness with a good adhesion to the substrate is realized. Moreover, limiting the extraction of Li from the electrode material by restricting the discharge cutoff potential may further improve the electrode lifetime (results not presented here). Indeed, one can very well imagine that a smaller shrinkage of the electrode is achieved when the amount of extracted $\mathrm{Li}$ is limited, which in turn increases the material lifetime.

The kinetics of evaporated germanium was investigated with EIS during a GITT discharge of $\mathrm{Li}_{15} \mathrm{Ge}_{4}$. The corresponding Nyquist plots are shown in Fig. 6b. The impedance results show two depressed semicircles followed by a straight line. The width of the semicircle observed at high frequencies in Fig. $6 \mathrm{~b}$ is almost constant with respect to the potential and can therefore be attributed to an ionic conductor. The second semicircle is somewhat dependent on the potential and can be attributed to a charge-transfer process. The almost straight line observed at lower frequencies can certainly be related to the diffusion of $\mathrm{Li}$ species within the electrode material. 

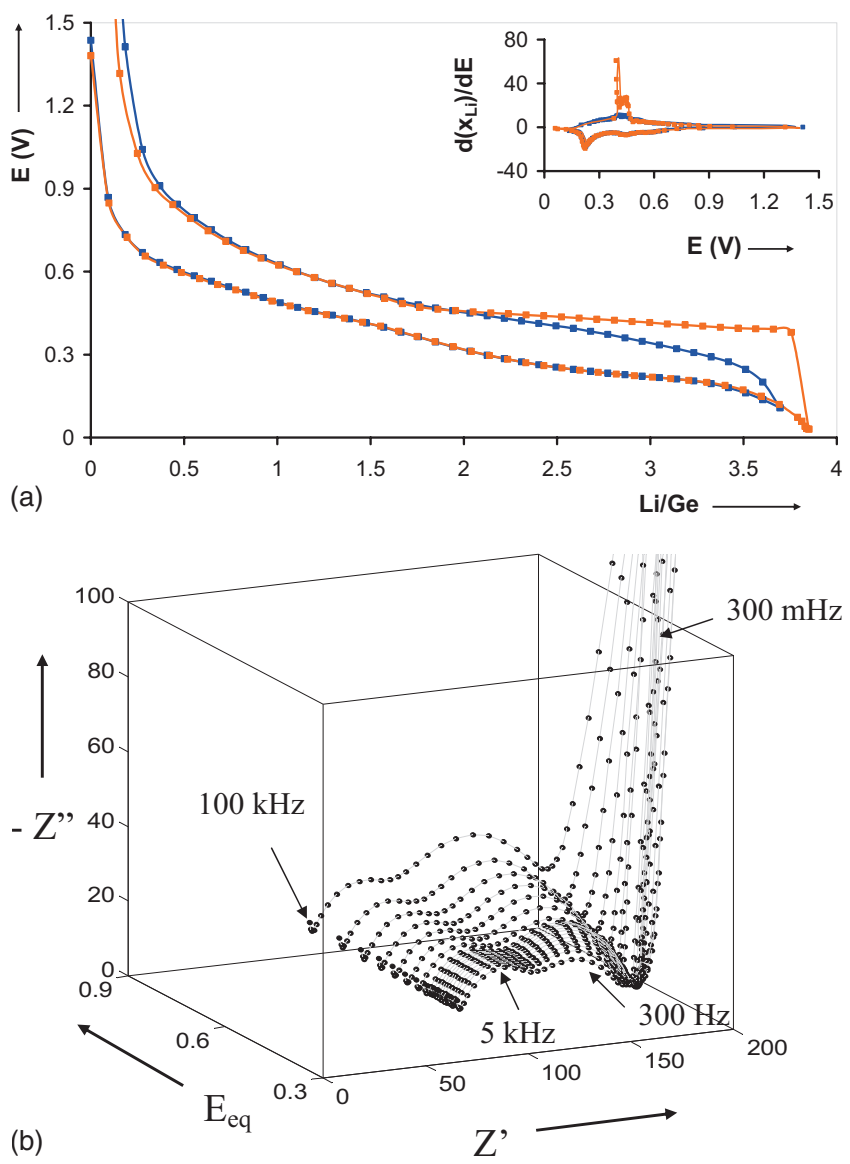

Figure 6. (a) Equilibrium curves of a $50 \mathrm{~nm}$ thick Ge film for two cutoff potentials, 0 (orange curve) and $50 \mathrm{mV}$ (blue curve), respectively. The corresponding derivative curves are shown in the inset. (b) Nyquist plots during a GITT discharge of a fully lithiated $\mathrm{Li}_{15} \mathrm{Ge}_{4}$ electrode.

A schematic representation of this electrochemical system and the corresponding equivalent circuit are presented in Fig. 7a. The equivalent circuit includes two series resistances for the ohmic contacts on both electrode sides $\left(R_{s 1}\right.$ and $\left.R_{s 2}\right)$, a liquid electrolyte $\left(R_{\text {elec }} \| C_{\text {elec }}\right)$, an SEI $\left(R_{\mathrm{SEI}} \| C_{\mathrm{SEI}}\right)$, a charge transfer $\left(R_{\mathrm{ct}}\right.$ and $\left.C_{\mathrm{dl}}\right)$, and a diffusion element $\left(Z_{\text {diff }}\right)$ response. The resistance $R_{\text {elec }}$ represents the ionic resistance of the liquid electrolyte between the reference and working electrodes, and $C_{\text {elec }}$ the corresponding geometric capacitance. The resistance $R_{\mathrm{SEI}}$ represents the ionic resistance of the SEI film and $C_{\mathrm{SEI}}$ the corresponding geometric capacitance. The charge transfer $\left(R_{\mathrm{ct}}\right.$ and $\left.C_{\mathrm{dl}}\right)$ and diffusion are represented by a classical Randles circuit into which the Warburg element is substituted by a diffusion element $\left(Z_{\text {diff }}\right)$ that can describe any type of diffusion process.

The very high-frequency domain $(>50 \mathrm{kHz})$ is normally dominated by the liquid electrolyte response and the low-frequency domain by the diffusion of lithium within the host material. These two domains are not of direct interest for the present study and the following simplifications have been made. The straight line observed at frequencies lower than $10 \mathrm{~Hz}$ in Fig. $6 \mathrm{~b}$ and making an angle smaller than $90^{\circ}$ with the $x$-axis can be represented by an $R \| C$ component in which $R$ has a relatively large value. As the low-frequency limit of the EIS experiments was set to $100 \mathrm{mHz}$, a good approximation of the straight line can be done by adopting a constant phase element $\left(\mathrm{CPE}_{\mathrm{diff}}\right)$. Moreover, the response of the liquid electrolyte above $50 \mathrm{kHz}\left(R_{\text {elec }} \| C_{\text {elec }}\right)$ can be restricted to a resistor which represents the ionic resistance between the working and reference electrodes. This resistance can be included with the ohmic contact $R_{s 1}$ $\underline{\text { Schematic representation of the electrochemical system }}$

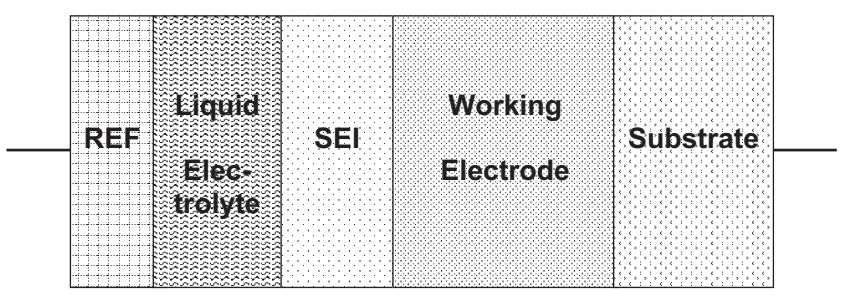

Corresponding equivalent circuit

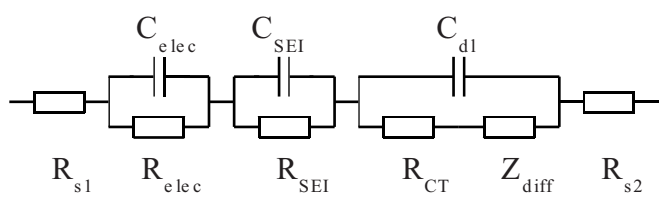

Modified equivalent circuit

(a)
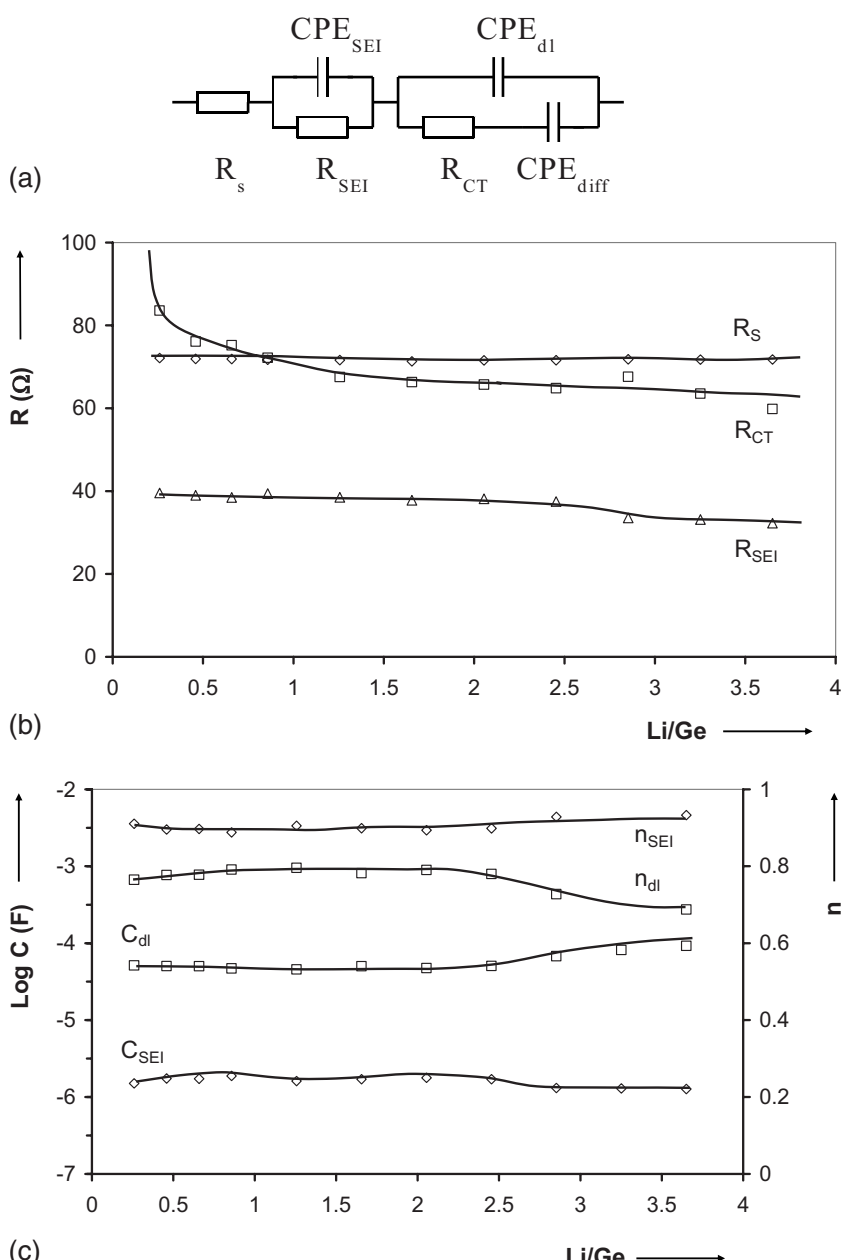

Figure 7. (a) Schematic representation of the electrochemical system, corresponding equivalent circuit, and modified equivalent circuit. The various components of the equivalent circuits are described in the text. (b) Resistances and (c) capacitances of the electrochemical system during a GITT discharge of $\mathrm{Li}_{15} \mathrm{Ge}_{4}$. The values are obtained after fitting the results of Fig. $6 \mathrm{~b}$ with respect to the modified equivalent circuit presented in (a).

and $R_{s 2}$ resistances into the purely resistive component $R_{\mathrm{S}}$.

The depressed semicircle observed at high frequency $(5 \mathrm{kHz})$ in Fig. $6 \mathrm{~b}$ is related to ionic conduction as it is almost independent of 


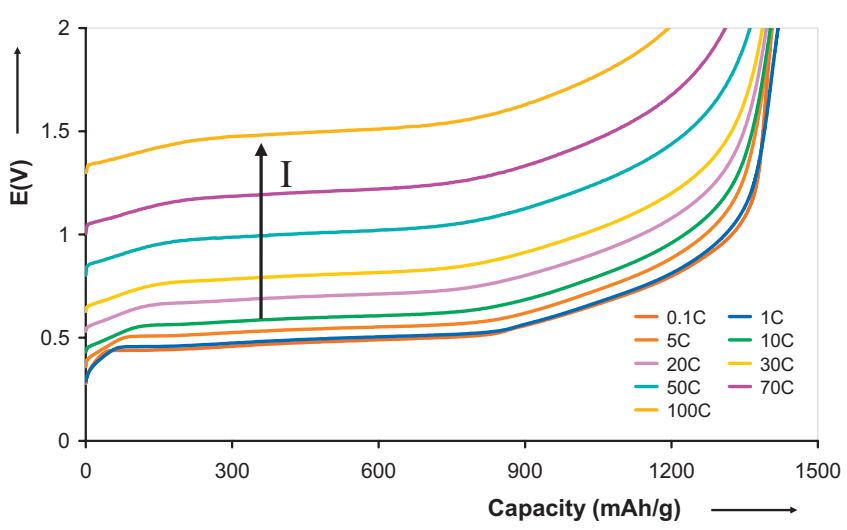

Figure 8. Discharge rate-capability measurements of a fully lithiated $50 \mathrm{~nm}$ thick germanium electrode, i.e., crystalline $\mathrm{Li}_{15} \mathrm{Ge}_{4}$. The potential is plotted as a function of the discharge capacity for various currents from 0.1 to $100 \mathrm{C}$ rate.

the equilibrium potential. Therefore, it certainly represents the ionic conduction through an SEI layer. The somewhat more depressed semicircle measured at intermediate frequencies $(300 \mathrm{kHz})$ certainly relates to a charge-transfer process, as it is potential-dependent. Thus, it is most probably representative of the charge transfer at the $\mathrm{SEI} / \mathrm{electrode}$ interface. The roughness of the electrode [as observed for similar electrode systems by ex situ scanning electron microscopy ${ }^{3,4}$ or in situ atomic force microscopy ${ }^{21}$ ) probably explains why the semicircles are somewhat depressed. As a result, CPEs were adopted instead of pure capacitors for the SEI (CPESEI and double-layer $\left(\mathrm{CPE}_{\mathrm{dl}}\right)$ charge accumulation processes, as shown in the modified version of the equivalent circuit presented in Fig. 7a.

By fitting the experimental data shown in Fig. $6 \mathrm{~b}$ with respect to the modified equivalent circuit shown in Fig. 7a, resistance, capacitance, and $n$ values for the various components of the equivalent circuit were extracted. The results are summarized in Fig. $7 \mathrm{~b}$ and c. The resistance and capacitance values associated with an ionic conductor are almost independent of the Li composition. The capacitance is between 1.3 and $1.9 \mu \mathrm{F}$ for an electrode having a footprint geometry of $2 \mathrm{~cm}^{2}$. This is characteristic of a solid ionic conductor and certainly results from an SEI layer, similarly to what has been reported for poly-Si electrodes. ${ }^{4}$ The double-layer capacitance is almost constant for compositions up to $2.5 \mathrm{Li} / \mathrm{Ge}$ (about $50 \mu \mathrm{F}$ ) and increases for higher Li compositions up to $90 \mu \mathrm{F}$ for the highest $\mathrm{Li}$ content. This increase certainly results from a more complicated fit, as can also be concluded from the corresponding $n$ values. The charge-transfer resistance decreases with increasing Li content (Fig. $7 \mathrm{~b})$. This is analogous to the poly-Si system. ${ }^{4}$ In addition, low values of $R_{\mathrm{ct}}$ are obtained, which implies that the rate at which electrons are transferred at the germanium/SEI interface is relatively fast.

The beneficial charge-transfer properties are further illustrated by measuring the rate capability of evaporated germanium during delithiation. The fully lithiated germanium electrode, i.e., $\mathrm{Li}_{15} \mathrm{Ge}_{4}$, was discharged from a $0.1-100 \mathrm{C}$ rate (Fig. 8). Similar potential profiles and high capacities are obtained for all currents up to a 100 $\mathrm{C}$ rate, which indicates the very favorable rate capability of these germanium thin film electrodes. These results confirm the beneficial charge-transfer kinetics previously observed with EIS, and also indicate that the solid-state diffusion of lithium within these thin germanium films is quite favorable.

The difference of the electrochemical deinsertion response between evaporated and sputtered germanium thin films $(50 \mathrm{~nm})$ is visualized in Fig. 9. During insertion of $\mathrm{Li}$, similar peaks are observed for both materials, which certainly indicates that evaporated and sputtered germanium undergo the same insertion reactions with Li. However, the peak positions are slightly different, particularly for the two small peaks observed at the end of the lithiation process.

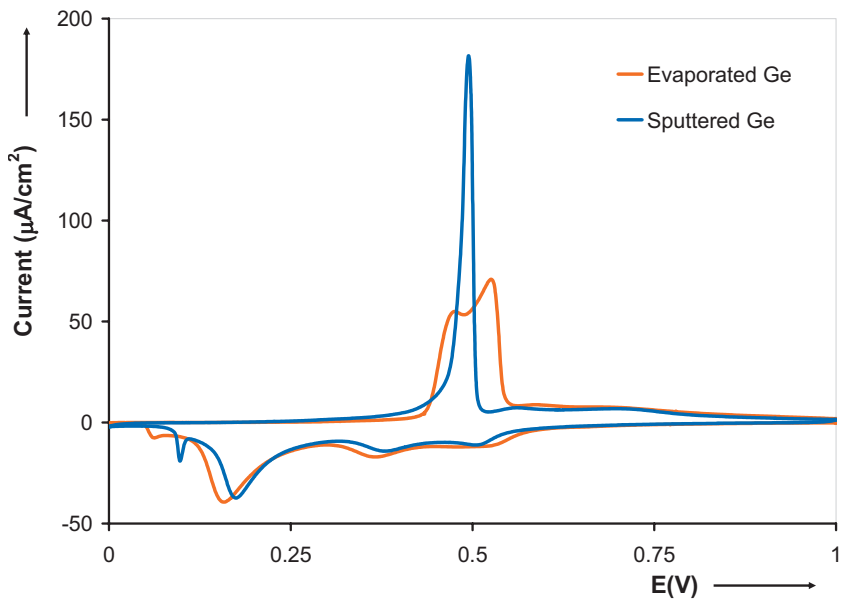

Figure 9. Cyclic voltammograms of $50 \mathrm{~nm}$ thick evaporated (orange) and sputtered (blue) Ge films between 0 and $1 \mathrm{~V}$ at a scan rate of $50 \mu \mathrm{V} \mathrm{s}{ }^{-1}$.

This difference can either originate from different equilibrium potentials (thermodynamics) or charge transfer, nucleation, or diffusion overpotentials (kinetics), which must be related to different material structures and defect densities. Upon extraction of Li from the fully lithiated material, sputtered germanium shows a sharp and intense peak at about $495 \mathrm{mV}$, while evaporated germanium presents the double-peak response. The reason for this difference is not clear yet. It probably results from differences in structural ordering, similar to what is observed during insertion.

The differences between evaporated and sputtered germanium, as observed in Fig. 9, has also been investigated with in situ XRD. Figure 10a shows the constant current charge and discharge profile of a $200 \mathrm{~nm}$ thick sputtered film. A small and flat plateau is again observed at the beginning of charging at around $0.6 \mathrm{~V}$. It can be attributed to the SEI formation, as reported by others. ${ }^{7}$ Upon (de)insertion, reactions similar to the cyclic voltammogram shown in Fig. 9 are observed. XRD patterns were collected during (de)insertion. Figure 10b shows the XRD patterns taken at the end of the insertion and at the start of the deinsertion process, as indicated by the markers in Fig. 10a. No diffraction peaks, except that of titanium nitride, are visible before the plateau observed at the end of charging. Once the plateau is reached, only diffraction peaks of the $\mathrm{Li}_{15} \mathrm{Ge}_{4}$ cubic phase are observed. This situation is similar to that of evaporated germanium, where only diffraction peaks resulting from $\mathrm{Li}_{15} \mathrm{Ge}_{4}$ are measured. This composition means that the maximum storage capacity of germanium thin-film electrodes is $1385 \mathrm{mAh} \mathrm{g}^{-1}$ or $7366 \mathrm{mAh} \mathrm{cm}{ }^{-3}$ of the starting material. Unfortunately, XRD could not reveal a difference in reaction between evaporated and sputtered germanium with $\mathrm{Li}$ ions. Therefore, more in-depth research is required. This could be achieved by means of advanced investigation techniques that are able to describe amorphous media, for instance extended X-ray absorption fine structure or nuclear magnetic resonance.

\section{Conclusions}

The thermodynamic and kinetic properties of evaporated germanium were investigated by means of conventional electrochemical tools. Evaporated and sputtered germanium thin films were investigated by means of in situ XRD to reveal the formed crystalline phases and the end member of the $\mathrm{Li}-\mathrm{Ge}$ electrochemical system. The electrochemical equilibrium and impedance data suggest that evaporated germanium is a promising candidate as a lithium-ion negative electrode thin-film material. The in situ XRD results show that both types of germanium crystallize into cubic $\mathrm{Li}_{15} \mathrm{Ge}_{4}$ at full lithiation. The difference in reaction observed between evaporated and sputtered germanium could not be revealed using in situ XRD and needs to be investigated further. Nevertheless, it can be con- 


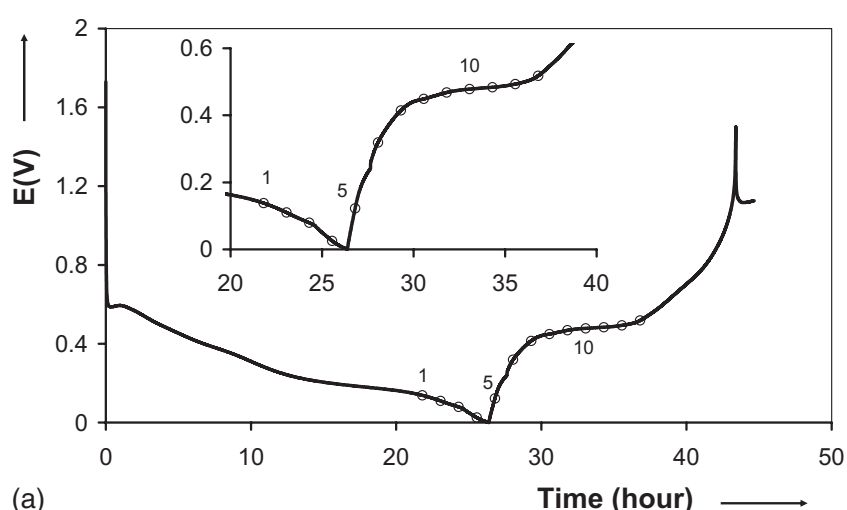

(a)

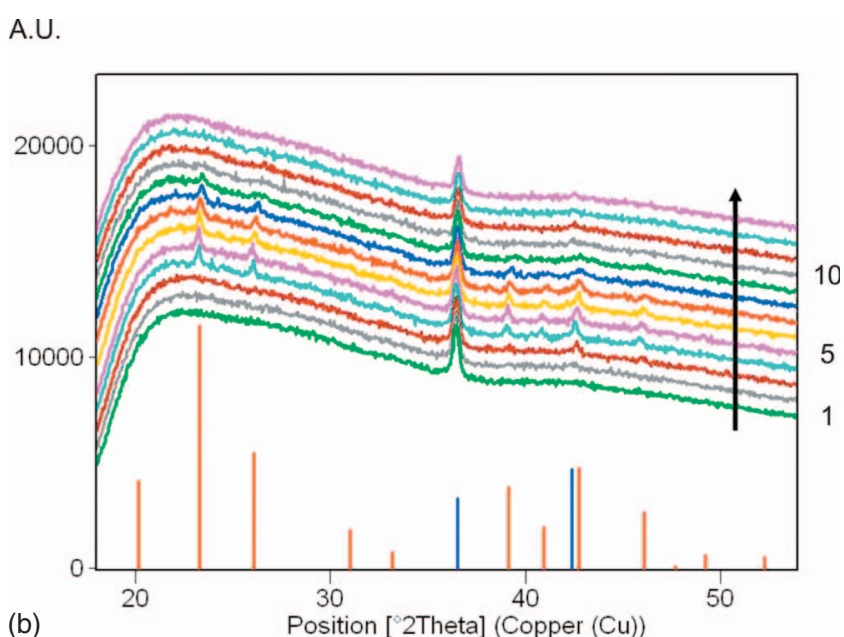

Figure 10. In situ XRD characterization of a $200 \mathrm{~nm}$ thick sputtered Ge film. (a) Galvanostatic insertion and deinsertion of the electrode. The inset is a magnification of the potential curve. Each marker represents the start of an XRD scan. (b) XRD patterns before and after the plateau visible at low potentials, corresponding to the markers shown in (a). The reference patterns for TiN (blue) and $\mathrm{Li}_{15} \mathrm{Ge}_{4}$ (orange) are indicated as bars.

cluded from this study that the end member of the Li-Ge electrochemical thin-film system is $\mathrm{Li}_{15} \mathrm{Ge}_{4}$. This composition means that the maximum storage capacity of germanium thin-film electrodes is $1385 \mathrm{mAh} \mathrm{g}^{-1}$ or $7366 \mathrm{mAh} \mathrm{cm}^{-3}$ of the starting material.

\section{Acknowledgments}

Jeroen van Zijl, Martien Maas, Emile van Thiel, Robert van Teeffelen, Tiny den Dekker, and Loc Quang Huynh are gratefully acknowledged for the preparation of the various samples. The authors are indebted to Harry Wondergem, Rogier Niessen, and Paul Vermeulen for fruitful discussions. This research has been financially supported by the Dutch Science Foundation SenterNovem.
Eindhoven University of Technology assisted in meeting the publication costs of this article.

\section{References}

1. M. Armand and J.-M. Tarascon, Nature (London), 451, 652 (2008).

2. P. H. L. Notten, F. Roozeboom, R. A. H. Niessen, and L. Baggetto, Adv. Mater (Weinheim, Ger.), 19, 4654 (2007).

3. L. Baggetto, R. A. H. Niessen, F. Roozeboom, and P. H. L. Notten, Adv. Funct. Mater, 18, 1057 (2008)

4. L. Baggetto, J. F. M. Oudenhoven, T. van Dongen, J. H. Klootwijk, M. Mulder, R. A. H. Niessen, M. H. J. M. de Croon, and P. H. L. Notten, J. Power Sources, In press. [DOI: 10.1016/j.jpowsour.2008.07.076]

5. J. B. Bates, N. J. Dudney, B. Neudecker, A. Ueda, and C. D. Evans, Solid State Ionics, 135, 33 (2000).

6. J. Graetz, C. C. Ahn, R. Yazami, and B. Fultz, J. Electrochem. Soc., 151, A698 (2004).

7. B. Laforge, L. Levan-Jodin, R. Salot, and A. Billiard, J. Electrochem. Soc., 155, A181 (2008).

8. Y. Hashimoto, N. Machida, and T. Shigematsu, Solid State Ionics, 175, 177 (2004).

9. Y. Kim, H. Hwang, K. Lawler, S. W. Martin, and J. Cho, Electrochim. Acta, 58 , 5058 (2008).

10. S. Yoon, C.-M. Park, and H.-J. Sohn, Electrochem. Solid-State Lett., 11, A42 (2008).

11. P. Poizot, S. Laruelle, S. Grugeon, L. Dupont, and J.-M. Tarascon, Nature (London), 407, 496 (2000)

12. R. A. Huggins, J. Power Sources, 81-82, 13 (1999).

13. U. Kasavajjula, C. Wang, and A. J. Appleby, J. Power Sources, 163, 1003 (2007).

14. M. Uehara, J. Suzuki, K. Tamura, K. Sekine, and T. Takamura, J. Power Sources, 146, 441 (2005).

15. K. Yoshimura, J. Suzuki, K. Sekine, and T. Takamura, J. Power Sources, 146, 445 (2005)

16. M. Suzuki, J. Suzuki, K. Sekine, and T. Takamura, J. Power Sources, 146, 452 (2005)

17. Y. Wang and J. R. Dahn, J. Electrochem. Soc., 153, A2314 (2006).

18. T. D. Hatchard and J. R. Dahn, J. Electrochem. Soc., 151, A838 (2004)

19. M. N. Obrovrac and L. Christensen, Electrochem. Solid-State Lett., 7, A93 (2004)

20. L. Y. Beaulieu, K. W. Eberman, R. L. Turner, L. J. Krause, and J. R. Dahn, Electrochem. Solid-State Lett., 4, A137 (2001).

21. L. Y. Beaulieu, T. D. Hatchard, A. Bonakdarpour, M. D. Fleischauer, and J. R. Dahn, J. Electrochem. Soc., 150, A1457 (2003).

22. P. Limthongkul, Y.-I. Jang, N. J. Dudney, and Y.-M. Chiang, Acta Mater, 51, 1103 (2003).

23. S.-J. Lee, J.-K. Lee, S.-H. Chung, H.-Y. Lee, S.-M. Lee, and H.-K. Baik, J. Power Sources, 97-98, 191 (2001).

24. J. P. Maranchi, A. F. Hepp, and P. N. Kumta, Electrochem. Solid-State Lett., 6 , A198 (2003).

25. H. Jung, M. Park, S. H. Han, H. Lim, and S.-K. Joo, Solid State Commun., 125, 387 (2003).

26. Y. J. Park, K. S. Park, M. K. Kim, J. G. Kim, M. K. Kim, H. G. Kim, and H. T. Chung, J. Power Sources, 88, 250 (2000).

27. M. Mohamedi, S.-J. Lee, D. Takahashi, M. Nishizawa, T. Itoh, and I. Uchida, Electrochim. Acta, 46, 1161 (2001).

28. S. C. Nam, Y. S. Yoon, W. I. Cho, B. W. Cho, H. S. Chum, and K. S. Yun, Electrochem. Commun., 3, 6 (2001).

29. I. A. Courtney and J. R. Dahn, J. Electrochem. Soc., 144, 2045 (1997).

30. I. A. Courtney and J. R. Dahn, J. Electrochem. Soc., 144, 2943 (1997).

31. I. A. Courtney, W. R. McKinnon, and J. R. Dahn, J. Electrochem. Soc., 146, 59 (1999).

32. B. J. Neudecker, R. A. Zuhr, and J. B. Bates, J. Power Sources, 81-82, 27 (1999).

33. N. Pereira, L. C. Klein, and G. G. Amatucci, J. Electrochem. Soc., 149, A262 (2002).

34. N. Pereira, M. Balasubramanian, L. Dupont, J. McBreen, L. C. Klein, and G. G. Amatucci, J. Electrochem. Soc., 150, A1118 (2003).

35. N. Pereira, L. Dupont, J.-M. Tarascon, L. C. Klein, and G. G. Amatucci, J. Electrochem. Soc., 150, A1273 (2003)

36. K. S. Park, Y. J. Park, M. K. Kim, J. T. Son, H. G. Kim, and S. J. Kim, J. Power Sources, 103, 67 (2001).

37. P. Vermeulen, H. J. Wondergem, P. C. J. Graat, D. M. Borsa, H. Schreuders, B Dam, R. Griessen, and P. H. L. Notten, J. Mater. Chem., 18, 3680 (2008). 